\title{
Moving for Cures: Breast Cancer and Mobility in Italy
}

DOI:

10.1080/01459740.2019.1592171

\section{Document Version}

Accepted author manuscript

Link to publication record in Manchester Research Explorer

\section{Citation for published version (APA):}

Greco, C. (2019). Moving for Cures: Breast Cancer and Mobility in Italy. Medical Anthropology, 38(4), 384-398. https://doi.org/10.1080/01459740.2019.1592171

\section{Published in:}

Medical Anthropology

\section{Citing this paper}

Please note that where the full-text provided on Manchester Research Explorer is the Author Accepted Manuscript or Proof version this may differ from the final Published version. If citing, it is advised that you check and use the publisher's definitive version.

\section{General rights}

Copyright and moral rights for the publications made accessible in the Research Explorer are retained by the authors and/or other copyright owners and it is a condition of accessing publications that users recognise and abide by the legal requirements associated with these rights.

\section{Takedown policy}

If you believe that this document breaches copyright please refer to the University of Manchester's Takedown Procedures [http://man.ac.uk/04Y6Bo] or contact uml.scholarlycommunications@manchester.ac.uk providing relevant details, so we can investigate your claim.

\section{OPEN ACCESS}




\section{MOVING FOR CURES: BREAST CANCER AND MOBILITY IN ITALY}

\section{Cinzia Greco}

\section{AUTHOR ACCEPTED MANUSCRIPT, for final version please see}

https://doi.org/10.1080/01459740.2019.1592171

I combine the theoretical tools of medical anthropology and the framework of mobility studies to explore the intranational movements of women with breast cancer from Southern and Northern Italy. Differences include patients' technical and moral evaluations of doctors, that influence the patients' definitions of cure and illness experiences through their mobility and immobility. These (im)mobilities are, in turn, linked to the material and symbolic inequalities between Southern and Northern Italy and to the stigma attached to the south. These (im)mobilities suggest the need to further articulate the concept of cure.

\section{Abstract in Italian}

Combinando gli strumenti teorici dell'antropologia medica e il quadro teorico degli studi sulla mobilità, in questo articolo esploro i movimenti intranazionali delle donne con cancro al seno del sud e del nord Italia. Le differenze includono la valutazione tecnica e morale che le pazienti fanno dei medici, la quale influenza la definizione della cura e dell'esperienza di malattia delle pazienti attraverso la loro mobilità e immobilità. Queste (im)mobilità sono a loro volta legate alle ineguaglianze, simboliche e materiali tra il nord e il sud Italia e allo stigma legato al sud. Queste (im)mobilità suggeriscono la necessità di articolare più in profondità il concetto di cura. 
Keywords: Italy, breast cancer, cure, illness experience, inequalities, mobility

Running title: Moving for cures

Media teaser: Why do women with breast cancer in Italy move across the country for treatments they could have locally? What meaning do they attach to moving (or not) for treatments?

CINZIA GRECO is a Wellcome Trust Fellow at the Centre for the History of Science, Technology and Medicine at the University of Manchester. She specializes in the study of cancer and has further research interests in medical innovation, inequalities in access to healthcare, and gender and health. She is the recipient of the 2016 Barbara Rosenblum Dissertation Scholarship for the Study of Women and Cancer.

Centre for the History of Science, Technology and Medicine (CHSTM) Room 2.70 Simon Building, The University of Manchester Brunswick Street, Manchester, M13 9PL, UK cinzia.greco@manchester.ac.uk 
The work on migration for health largely focuses on international migration. In contrast, my focus is on intranational health-related mobilities, specifically of Italian women from both the south and the north of the country who have received a breast cancer diagnosis, and its relationship to the socio-political context of Italy. In Southern Italy, the movements to the north to receive treatment are frequent. This has an effect not only on the patients who move but also on those who remain in their region of residence because the meaning of cure, and therefore also the meaning of the illness and experiences related to it, are redefined by the decision to move or to stay. In analysing this (im)mobility (Salazar and Smart 2011), I integrate the understudied phenomena of immobility and intranational mobility in the study of medical travel and explore the search for cures as a specific logic of health-related mobility.

Medical travel (Whittaker, Manderson, and Carthwright 2010), also called medical migration (Roberts and Scheper-Hughes 2011), has become an established field of study, distinct from the scholarship on the health of migrants for economic, political, or family reasons (for a synthesis of the latter scholarship, see e.g., Castañeda 2010; Sargent and Larchanché 2011). Medical travel as an approach has allowed us to understand healthcare seeking beyond the local level (Kangas 2002). All major syntheses (Roberts and ScheperHughes 2011; Sobo 2009; Whittaker et al. 2010) have underlined that medical travel is also characterized by inequalities and suffering, contradicting the positive image promoted by the medical tourism industry (Sobo, Herlihy, and Bicker 2011). There are often marked inequalities between countries involved in international medical travel or medical migration, and between the people who make such journeys. Intranational inequalities and the consequent mobilities have been less explored.

In this article, I offer a three-fold contribution to the study of mobility and health. By 
reconceptualizing medical travel/medical migration as health-related mobility, I draw attention to the relevance of intranational mobilities and the impact of health-related mobility on the meaning of being treated locally. By bringing attention to the Italian context, in which universal healthcare coverage and availability of treatments exist, yet within which there are significant intranational mobilities, I highlight how health-related mobility can be informed by a logic of cure and not only by logics of access and healing. Such an approach allows a more comprehensive understanding of (im)mobility as a constituent component of health, rather than as an exceptional practice.

The mobility approach (Urry 2007; Glick-Schiller and Salazar 2013), developed within the larger field of migration studies, avoids dichotomies between international and intranational mobilities and between long-term, settlement-oriented mobilities and short-term, temporary mobilities (see also Pian 2015). Health-related mobilities within the limits of a national territory have primarily been the focus of policy-oriented, quantitative evaluations (e.g. Balzi et al. 2002). When anthropologists have taken interest in similar phenomena, it has predominantly been related to rural-urban mobilities (for exceptions, see Vindrola-Padros 2012; Vindrola-Padros and Brage 2016) and the difficulty of access to health services (e.g., Molina and Palazuelos 2014). "Migration" is usually used for long-term movement that can become permanent, but health-related mobilities can vary in their duration without necessarily implying long-term stays. I analyse both southern and northern Italian women's searches for cures, seen as an (im)mobility (Salazar and Smart 2011). I refer to "(im)mobility" as I consider both the experiences of women who moved to receive treatment and those who did not move or who did not define their mobility as "moving." Glick-Schiller and Salazar (2013) have underlined that it is not only movement that deserves theoretical and empirical attention, but that stasis and immobility, rather than being the norm, also need to be 
explained. Travelling to the north from Southern Italy for medical treatment and (desired) cure is widespread, which means that being treated in hospitals close to home is an immobility that requires justification or at least explanation. The concept of motility, which refers to the resources (Kaufmann, Bergman, and Joye 2004) and constraints (Leivestad 2016) that define the potential capacity to move, irrespective of actual mobility, further helps to understand (im)mobilities linked to medical treatments.

Most health-related migration research focuses on the Global North-Global South axis, but several studies have shown more complex itineraries, as patients often move to bordering countries that can both be geographically proximate and socially and politically similar (Kangas 2007; Vindrola-Padros and Whiteford 2012). Recent literature on mobility has further encouraged the abandonment of the linear model of health-related mobilities, instead considering them as complex experiences characterized by trial and error, obstacles, and the need to mobilize different resources, including money, knowledge and networks (Vindrola-Padros and Johnson 2015; Vindrola-Padros and Brage 2016). The focus on the Global North-Global South axis has made evident the mobilities informed by a logic of access - with people moving to the Global North to access treatments unavailable locally and to the Global South to access cheaper treatments. In this article, I show that doing research within the Global North can bring to the fore a logic of cure. I use "logic" to denote how different rationales can inform a specific practice, in this case mobility, following the use of "logic of care" and "logic of choice" in Mol's (2008) analysis of rationales in the organization of medical treatments.

The logic of access can include moving to a richer context from one in which a treatment is absent (e.g., Kangas 2002), moving to access experimental treatments or treatments that are not allowed locally (e.g., Inhorn, Shrivastav, and Patrizio 2012), or 
moving to places in which the treatment is more affordable (e.g., Dalstrom 2012). Other researchers (e.g., Parkin 2014) have shown a logic of healing that goes beyond assumptions related to biological effectiveness. "Cure" and "healing" have been linked respectively to disease and illness, with "cure" describing processes that tackle biological phenomena linked to the disease, and "healing" referring to remedies for the subjective experience of illness (e.g., Young 1982). Linking cure and biomedicine, on the one hand, and healing and complementary and alternative medicines on the other, has been criticized since both typologies of medicine can pursue both aims (Waldram 2000).

Breast cancer in Italy shows a logic of cure. Breast cancer is a life-threatening disease, and can push the patients to look for the best environment in which to be treated. At the same time, institutions able to treat the condition are common in Italy, and universal health care coverage limits the costs of treatment for patients, which means that the choice to move is not justified by the absence of the treatment in a specific territory or its cost. The patients I interviewed moved to undergo therapies in institutions where they had more confidence in the institution's capacity to cure them, that is, to resolve the biological problem of cancer.

In the following pages, I first locate the research within the context of the structural inequality between Southern and Northern Italy - called "Southern Question" by historians and politicians - and I discuss the Italian healthcare system as part of this structural inequality. I then present the experiences of the interviewed women, including southern women who moved to the north to receive treatments, southern women who remained in the south and justified their decision in the interview, and northern women who moved within the north to be treated. I conclude by observing that the relevance of (im)mobility and its meanings, especially for southern interviewees, constitutes a response to the stigma attached to their territory. 


\section{THE ITALIAN CONTEXT}

Italy is characterized by strong differences between the north and south of the country, with Northern Italy being described as industrialized and modern, while Southern Italy is seen as backward, scarcely industrialized, and economically dependent on the north. This gap, which dates back to the unification of the country in 1861, is usually termed the questione meridionale - the Southern Question. The Southern Question has been debated throughout the country's contemporary history, with many explanations given and solutions proposed. Beyond early biologistic explanations, such as those given by Alfredo Niceforo (see Cimino and Foschi 2014), the gap between the south and north of the country has been seen as the consequence of a lack of efficient local institutions, as a result of the absence of a culture of solidarity beyond the nuclear family (Banfield 1958), or as the effect of corruption and links between organized criminality and the local political class. Other observers consider the gap the result of economic underdevelopment that should have been resolved by investments from the central government (this has been the approach of the Association for the Development of Industry in the Mezzogiorno - SVIMEZ; see Galasso 2006). However, the most convincing analysis remains that of Gramsci (1966, reprinting texts from the 1910s and 1920s), who saw the situation as the consequence of an "alliance" between the capitalist classes - northern industrials and southern landowners - in which Southern Italy was allocated a structurally subaltern role that was necessary for the northern economy. Gramsci's position excludes what many meridionalisti (advocates for the improvement of conditions in the south) proposed before and after him, that is, that the north-south gap could be closed through the development (whether economic, civic or cultural) of, or increased autonomy for, the south, without challenging the capitalistic organization of the economy of the whole country. While culturalist interpretations depicting the south as backward and lacking civic 
sense have been criticized since the early twentieth century, they still resurface periodically in Italian public debate, such that a cultural stigma attached to southerners is superimposed on the area's economic subalternity. Southern Italy is perceived as an internal other, and is often described through orientalist discourses in public debates (Schneider 1998). This is particularly relevant here, as such stigma against the population can combine with the stigma of having a disease; further, in specific cases, the disease may be attributed to the (presumed) cultural "backwardness" of the population and its (presumed) inability to follow healthy lifestyles (Greco 2016).

Economic disparity has been a catalyst for important migratory flows from southern regions to northern ones. These flows peaked after World War II, with the industrialization of Northern Italy and the resulting demand for workers. Internal migrations decreased, although never ceased, toward the end of the 1970s; nonetheless, they remain an important phenomenon in Italian society (cf. Buonomo and Gabrielli 2016).

Internal health-related mobilities in Italy are located within this social and political framework, besides being linked to the characteristics of the Italian healthcare system. The Italian National Health Service (Servizio Sanitario Nazionale - SSN) has been, since the end of the 1970s, a universal healthcare system. It aims to offer free healthcare services to all residents in Italy with the objective of maintaining the health and well-being of the population. For the present analysis, it is important to underline that all residents have the right to be treated in any public institution anywhere on the national territory without any specific authorization. A progressive taxation system supports the SSN (Toth 2014). However, several factors interfere with the application of this ideal model (Mapelli 2012; Toth 2014), undermining the quality of the treatments supplied. While private medical insurance is rare in Italy, there is a co-presence of public institutions and private healthcare 
organizations that varies from region to region (Toth 2014). Regions are the highest administrative division in Italy, and are subdivided into provinces and municipalities. Patients either pay for their treatments out of their own pocket (in the private sector) or cover part of the cost of their treatments (in the public sector). The latter contribution, called a "ticket," can sometimes be expensive.

Significant differences also exist in the quality of services supplied in the different regions. The autonomy of the regions in the domain of healthcare was significantly increased starting with the 1990s, then with a 2001 constitutional reform attributing jurisdiction over health policy to the regions, while the central government retained the authority to establish minimum standards (Livelli essenziali di assistenza - LEA). This contributed to rendering healthcare in Italy more complex and diverse (Toth 2014). It is generally assumed in everyday discourse that treatment provided in the southern regions is of lesser quality than that provided in the northern regions, both in terms of the quality of healthcare services and waiting time to access these services. This is reflected in the different levels of patients' satisfaction in the north and south (cf. Toth 2014).

Drawing on patients' mobility information from the analysis of patient discharge data, Pica and Villani (2010) showed that in 2007, more than 800,000 hospitalizations (including of patients for day procedures) took place outside of the patients' region of residence; of these one third were people from Southern Italy who had travelled to Northern Italy for treatment. These south-north movements, defined as viaggi della speranza - journeys of hope (Viesti 2001) - are well-known experiences of a large part of the Italian population. The already existing territorial inequality has been complicated in the last few years by cuts to services and measures to contain public expenses, which have been hastened as a result of the economic crisis. While the situation in the south has not improved (Gabriele 2015), the 
economic condition of the northern regions has also worsened (Svimez 2014).

\section{METHODS}

The ethnographic data that inform this analysis were collected as part of a larger comparative project focusing on women's experience of breast cancer treatments, and, in particular, of surgical treatments, in France and in Italy. This larger project included interviews with patients and medical professionals, participant observation of patients' association meetings, and meetings between medical institutions and patients' advocates. In this article I focus on interviews with 28 breast cancer patients conducted between 2012 and 2014 in two different Italian regions: Apulia, in Southern Italy, and Emilia-Romagna, in Northern Italy. In Northern Italy, I mainly contacted breast cancer patients through local cancer patients' associations, while in Southern Italy I mainly contacted patients with the help of female friends and relatives. The women interviewed came from both middle (professional and white collar) and working classes, but the difference in the contact procedures meant that there was a prevalence of working-class women among those interviewed in the south. However, interviewees from the south from a middle-class background brought up experiences and views similar to those of women with a working class background, suggesting that the prevalence of working class women among the southern interviewees did not alter my understanding of patients' experiences. The majority of the interviews were recorded, but in cases where the interviewee preferred not to be recorded, I took notes during and immediately after the encounter. In all cases, full oral consent was obtained before the start of the interview. The interviews were conducted in the form of open conversations revolving around the participants' experience of illness and were in Italian, but most of the interviewees from Southern Italy used code-mixing, that is, they switched between standard Italian and the 
local dialect, which I understand. This did not happen during interviews with northern Italian patients, perhaps because they knew that I could not understand northern Italian dialects. I translated the interview excerpts included in this article into English; all names used are pseudonyms and some minor personal details have been changed to protect the patients' privacy.

The methodological approach followed here was the extended case method (Burawoy 1991), in which ethnographic data are connected with existing theories and structural phenomena, i.e., larger social phenomena that cannot be fully grasped at the scale of observation, in order to situate the data and to identify the deviation of the data from the existing theories. In particular, I have linked patients' narratives with the available knowledge on the level of funding of the Italian public healthcare system, on the magnitude of both health- and non-health-related internal mobility in Italy, and on the country's history of geographical inequality. Documentary research supports the data collected in the fieldwork and includes an analysis not only of the medical literature on breast cancer, particularly surgical therapies, but also an analysis of legislative and juridical reports and the scientific literature on the economy of health and on health policies.

Insert Figure 1 here

\section{THE NORMALITY OF GOING NORTH FOR THE CURES}

In the following, I present three scenarios: southern women moving to north, southern women who stay in the south, and, finally, northern women moving within the north.

Several patients, after having received an initial breast cancer diagnosis in Southern Italy, sought treatment in medical centers far from the region in which they lived. It is not easy to take such a decision; for many, treatment in other regions can be costly and 
logistically difficult. Some patients go north because they believe that the quality of treatment that they will receive will compensate for the difficulties and the extra cost (compare the role of trust in the local medical system in Yemen, Kangas 2007). This was the case for Elena, a young woman living in the province of Brindisi, diagnosed with breast cancer when she was 29 years old. After her initial diagnosis, some medical professionals close to her family suggested that it would be better for her "to go north" for treatment, and her family strongly supported this advice. Elena decided to move because she thought that it would have been difficult to find treatment suited to a young woman with breast cancer in nearby medical centers. She decided to be treated in Lombardy at a center that she described as being "up to the job." Elena described the financial costs and the logistic problems that this decision entailed; however, she continued, her confidence that she was receiving the right treatments from medical professionals she trusted compensated for these difficulties. She added: "These are medical professionals who care about patients, not about their financial gain." While the importance of being treated by honest medical professionals who are not driven by financial motivations was a recurrent element in interviews with women from Southern Italy, here this argument was mobilized to justify somewhat opposing choices. Patients who decided not to move for treatment could employ the same line of argument, as I illustrate further below.

Elena was not the only woman who believed that the treatments she would receive in northern institutions were better suited to her particular case. Consolata, a woman in her sixties living in the southern province of Lecce, decided to undergo breast surgery in a northern institution because she believed that there she would be more likely to receive conservative surgery rather than a mastectomy. Personal reasons and medical reasons could also sometimes become entangled. Antonella was in her fifties and also lived in the province of Lecce. After diagnosis, she decided to be treated in Lombardy, and the fact that her son 
had moved there some years before facilitated her decision:

My son lives in Lombardy. He looked for information and told me that there is a clinic that is really at the vanguard in the research for breast cancer. And I was also convinced by the fact that in that clinic, I would have to undergo just one operation. In Lecce I would have had to undergo a first operation, then they would have analysed the sentinel lymph node, and, if it unfortunately turned out to be positive, I would have had to undergo a second operation for a radical axillary dissection. [In the clinic in Northern Italy] during the operation they send the pathologist the part of the breast they have removed and this lymph node and they are in communication with the pathologist ... The surgeon explained to me: "Madam, this kind of operation, that you would have undergone in Lecce, we used to do it 15 years ago." That is because of the structures, not because there are no good doctors in Lecce, but unfortunately Lecce lacks the machinery and the structures.

As a result of the long history of internal migration in Italy, a significant part of the southern Italian population has a relative living in the north of the country. However, not everybody can rely on personal resources to facilitate health-related mobility as Antonella could (for similar patterns in international health-related mobility, see Pian 2015). Moreover, as Antonella's and Consolata's experiences show, medical reasons can justify the decision to be treated in a northern institution. Antonella preferred to undergo surgery in a clinic in Lombardy because it enabled her to avoid having a second operation. The frozen-section examination of the sentinel lymph-nodes, the intervention to which Antonella appears to refer, is considered a widespread practice in the medical literature (Barakat et al. 2014). This is due to the fact that, if malignant cells are found in the lymph nodes, this diagnostic technique can spare the anguish and the cost of a second operation. However, there are no 
data on how the prevalence of this practice varies between Northern and Southern Italy.

On the other hand, several factors can influence the medical choice that was relevant in Consolata's case, between a conservative breast operation or a complete mastectomy, including the size of the breast and the size, position and biology of the tumor (Clough et al. 2010). Surgeons themselves can have different opinions on whether to carry out a conservative operation or a mastectomy (Liberati et al. 1991); and a study has shown that in Italy, the choice between the two interventions does not appear to vary significantly along the south-north axis (Zorzi and Guzzinati 2011). These experiences do not tell us about the actual differences between hospitals in the north and south, as much as they tell us about representations of Southern Italy. These are representations that depict the south as belonging in the past or as less modern than the north. Women who move can experience greater logistical difficulties but, when explaining their decision, they may resort to an established imaginary about the differences between the north and the south. I do not mean to diminish the differences between, and problems in, the healthcare services that have been highlighted, especially by studies on healthcare economics. Rather, I wish to emphasise the plurality of elements that can matter for patients in their search for treatment, and ideally a cure, that fits them best. These elements are embedded in social contexts - the north-south difference - and can include specific moral or technical expectations - a greater honesty among the doctors or the type of procedures available. This plurality also emerges from the experiences of women who remained in the south for their treatments.

\section{STAYING IN THE SOUTH}

Patients who were treated in southern regions and did not move north were aware of the fact that the southern Italian health system is considered less efficient, and the discursive 
strategies they employed in describing their illness experience took this aspect into consideration. An important element characterizing the interviews with southern women was their use of spatial deixis. Adverbs of place, such as up/down, here/there and above/under, structured their narratives. Although these are common elements of the language, in the interviews collected they were used not only to refer to physical places, but also to express a geography of oppositions characterizing Italian territory and society. It is not always possible in translation to convey the semantic space outlined by this spatial deixis, but it is an important element showing how southern women situate themselves and their illness experiences. In almost all interviews, women brought up where they had been treated even if I did not explicitly ask them. Some patients explained their choice in a few words. For example, Carola, a woman in her sixties, said at the beginning of her interview: "I stayed here, I didn't go north (al Nord); after all, if it is going to go well, it will go well anywhere." Other women gave more articulate explanations of their decision to stay. Lucrezia, a woman in her forties living in Lecce, pointed out that the medical profession in Southern Italy was generally less lucrative than in Northern Italy, and she believed that medical professionals working in her region were therefore less motivated by money. This was one of the first elements to emerge when she described the first meeting with her surgeon, who worked in a hospital in Bari, the main city of the Apulia region:

A head physician [primario in Italian] who quickly gives you an appointment... I realized immediately that the doctors were not greedy at all, they were not interested in earning money, but simply do [their job] because they are convinced that it is something that has to be done, and this obviously gave me lot of trust. Because you can go to Milan, to the best institute we have in Italy, but before you get in they have emptied your pockets. They surely do their job with 
professionalism, but they also do it for the money, and I can understand this, but in some cases this goes to the limits... of ethics.

The two scenarios that Lucrezia contrasted are not exactly clear - perhaps she is comparing the experiences of a private sector patient in Milan and a public sector patient in Bari. However, the moral coloring of the discourse is significant, as it positively valorized the south in opposition to the north (thus inverting Elena's judgement, above), even though it still recognized the techno-scientific prestige of the latter.

In other cases, the decision to be treated locally was because patients did not consider the local healthcare system to be less effective. Several women emphasized the homogeneity of the Italian healthcare system, considering it capable of offering a service of overall good quality. This was why Doriana and Luciana, two women in their fifties living in the province of Lecce, decided to be treated in nearby hospitals. Doriana explained that her oncologist had studied in Lombardy, at a renowned medical center in Milan, and that he was therefore able to offer his patients in Lecce the same quality of treatment that they would have received in Milan: "[The doctor] was in Milan [and he was told]: 'you should go to work in Lecce, so that patients from Lecce would not need to come here any more. Why should they come here? To trouble their family?' And that's why he came here, he says."

Like Doriana, Luciana remained in Apulia, but before starting treatment she asked around, and several people suggested that she contact a doctor who had previously worked in Lombardy. When she started treatment with this doctor, another element reassured her of the quality of the healthcare she was receiving. In the waiting room, Luciana met a woman who had also been diagnosed with cancer. Several years earlier, at the age of 17, this woman had been successfully treated for a lymphoma in Milan. But this time, she told Luciana, upon receiving her second diagnosis, she decided to remain in the province of Lecce because she 
thought that the quality of the institution where both she and Luciana were being treated was no different from the institutions in Lombardy. The information that Luciana had gathered from friends and acquaintances before and during her therapy convinced her that there was no need "to go up [north]" (andare sopra), because in her province there were good institutions and it was just a matter of finding them. Indeed, she believed that "sometimes we have excellent doctors here and we just don't know it."

Celeste, a woman in her sixties, told me that after her mastectomy, she was uncertain as to whether to undergo a breast reconstruction; one of the main obstacles was that she thought she would have to have the operation in Milan. Some years before, with the help of her niece who lives in Milan, Celeste had set everything in place to have a reconstruction. But at the last moment, she was so afraid of being operated on in a city so far from home that she cancelled the operation. A few years before the interview, a doctor had asked her during a check-up visit why she had not had a breast reconstruction, suggesting that it would have not been necessary for her to go to Milan. Celeste explained:

I said: “Doctor, I don't want to go to Milan". [And the doctor replied]: “What Milan! There's a surgeon here." He gave me the number of this surgeon, I called him and I went to see him in his office and [the surgeon, during the visit told me]: "Madam, if you want we can fix a date, you will be hospitalized for a couple of days and then you will undergo a breast reconstruction.” And that's what I did, I had the operation in Brindisi and everything went well.

A range of factors converge to orient women from Southern Italy in their therapeutic pathways. These pathways can entail a medium-range mobility, as the case of Lucrezia shows. Even some patients treated within their own province of residence described experiences that included up to three different hospitals, each located in a different town, in 
order to undergo different therapies. However, the main difference for southern interviewees was whether or not their pathway involved travelling to Northern Italy. Their financial circumstances, and the possibility of being able to afford treatment in regions far from home, played an important role, but other elements also influenced their decisions. The experience of friends, family and other patients, as well as the professional path of medical professionals, can contribute to shape the contours of healthcare landscapes in Southern Italy.

The literature on mobility has drawn attention to the importance of the imaginary, both in encouraging mobility and in aspirations among those who do not have the motility resources to migrate (e.g., Leivestad 2016). In the interviews I conducted, however, this aspect was less pronounced, probably because the imaginary might have a more limited role in an experience of illness and treatment that remains painful regardless of the location of the therapies. The imaginary seems to have limited the willingness of some interviewees to move, as in the case of Celeste, who cancelled her operation in Milan because she imagined that undergoing surgery far from home would have been too difficult. More generally, the patients who I interviewed who decided to remain in Southern Italy for their treatments were more interested in redefining positively their local experience than in imagining an experience in the north, although the legitimation of the healthcare in the south is partly motivated through its links to the north.

Patients who were treated locally were confronted with the widespread idea that the quality of healthcare is better in Northern Italy. In many cases, they did not agree and challenged this notion using different material (i.e., health-seeking) and discursive strategies. Several patients felt reassured by the fact that the medical professionals they met had studied in Northern Italy; Lombardy was frequently mentioned as home to several leading cancer treatment institutions. The mobility of physicians between different institutions was seen as a 
sign of treatment quality by the interviewees. After having studied at the best medical institutions of Italy, these doctors had returned to their region of origin in the south, ensuring that patients from the south could avoid moving north to receive adequate treatment. The mobility of medical professionals seems to reinforce the idea that the therapies available to patients, particularly for diseases like cancer, are the same across the national territory, not only because of nationally defined protocols but also because of the circulation of medical skills. This is exemplified in a passage from my conversation with Luciana. While talking about her chemotherapy, her son, who was present during the interview and who had closely followed his mother's treatments, pointed out that guidelines for the management of chemotherapeutic protocols are the same nationwide. Anthropologists and historians have often stressed that biomedicine is not homogeneous nor monolithic (Finkler 2000; Löwy 2007; Mol and Berg 1998); that knowledge and the practices of biomedicine vary over time and in space; and that local knowledge and practices model the illness experience within the borders of biomedicine. These interviews showed a strategic use of the concept of homogeneity of biomedical knowledge (cf. Dalstrom 2013). Such homogeneity, whether considered essential to biomedicine or deriving from the movements of doctors within the national territory, reassured patients and their relatives and supported the idea that they could receive good quality treatments, even if they remained in Southern Italy. The moral and technoscientific contexts evoked in the interviews were not dissimilar among southern and northern women, as I present in the following section.

\section{MOVEMENTS WITHIN THE NORTH}

The patients I met in Southern Italy were not the only women to move in search of breast cancer therapies. Some of the women I met in Emilia-Romagna had been treated in provinces 
or regions outside of their place of residence. In these cases, mobility assumed a different value. Morgana, a woman living in Emilia Romagna who was diagnosed with breast cancer before the age of 40 , described in a long interview a complex therapeutic trajectory. She visited several doctors in Emilia-Romagna and Lombardy, with the dual objective of obtaining adequate breast cancer treatments and preserving her fertility. In her experience, it was fundamental to have access to therapies enabling her to retain the possibility of having children.

Like Morgana, Claudia, another woman I met in Emilia-Romagna, had to build a personalized therapeutic trajectory according to which she underwent different therapies in different regions. Claudia was 40 when I interviewed her, but she had first discovered a lump in her breast shortly before turning 30 . The first doctor she saw reassured her that she was too young to have breast cancer. The histologic test, however, confirmed the presence of a malignancy. Claudia was in shock when she asked the doctor for information, the response to which was a recommendation to "speak with the oncology service."

There was no link. They told me to go to oncology... A photocopied sheet and they told me to go to oncology. And then something set off: in the two following days, I went to Mantua for an examination. [And I forgot to say that] in the photocopy, they talked of a cancer, but also that they had found a metastasis. And the first thing that they thought was that the primary cancer was in my head. But I refused to accept that it was a metastasis. Starting from there, within 24 hours I went to Mantua and then to Pisa. In Mantua the doctor did not think that it was a metastasis at all [because, according to him,] I was too well to be so ill. Then, he asked me to redo the tests on the slides. I went [to Emilia-Romagna] and I took the slides to send to Mantua. Meanwhile, as he was a physician, he told me: "You 
should know that, whatever the diagnosis, there will be another surgical intervention", and he wisely told me: "Start looking for a surgeon." And so the next stage was to go to Pisa, because there, thanks to some friends, I had a lead. There was a surgeon who operated on the breast doing the reconstruction during the first intervention, something that absolutely was not the case here, in this territory.

Claudia's history is probably atypical: her young age and the difficulties associated with her diagnosis made her trajectory particularly difficult. Unsatisfied with the behavior of the doctors and with the organization of the hospital, Claudia decided to take herself to see specialists working in neighboring regions, consulting an oncologist in Lombardy and a surgeon in Tuscany. After undergoing surgery in Tuscany, she however then decided to undergo chemotherapy at the hospital in the province where she lived. Claudia's and Morgana's youth, and their specific needs, justified their needs for a personalized therapeutic trajectory. Their stories also illustrate a healthcare system in Northern Italy that is fragmented, as the two women only managed to respond to their medical needs through what might be considered a bricolage of different institutions and doctors.

Most patients I interviewed in Northern Italy were treated in their province of residence. Medical institutions in Northern Italy are usually considered to be of high quality, and several hospitals in Emilia-Romagna have an excellent reputation. Such prestige is generally linked to the idea that healthcare in the north reaches higher professional standards, although such standards are not precisely defined in everyday discourse. This does not mean that the patients I met in Northern Italy did not experience difficulties in their therapeutic trajectories. Some still needed to navigate the local healthcare institutions and referred to conflicts with medical professionals, delays and bureaucratic problems. The economic crisis 
that started at the end of the 2000s had a negative impact on the healthcare systems of several southern European countries, and while the best known case of this is probably Greece, other countries, including Portugal, Spain and Italy, saw their healthcare resources reduced (Gabriele 2015). In Italy, the politics of retrenchment certainly had an impact on the country as a whole, but they were also linked with administrative reforms with decentralized healthcare policies (Gabriele 2015). This worsened conditions in more fragile regions, such as those in the south. The nature of responses to the financial crisis, combined with other characteristics of Northern Italy, such as lower unemployment rates, limited, at least in part, the effects of austerity and cuts to healthcare. In particular, one of the key factors of motility, the configuration and accessibility of the transport infrastructure (cf. Urry 2007: 190-194), saw a more favorable situation in Northern Italy than in the south, and can render local health-related mobilities less challenging for patients in the north.

\section{MOVING FOR CURES: ANALYSIS AND CONCLUSIONS}

For the southern Italian patients who I interviewed, health-related (im)mobility had important implications for their therapeutic trajectories. In this account, I have highlighted the relevance of intranational health-related mobility and how health-related mobility influences also those who do not move. This is one of the few studies to have focused on health-related intranational mobilities and, in particular, one of the few to have focused on the context of the universal healthcare systems of Western Europe. Analysing this kind of mobility enables inequalities, characteristic also of these healthcare systems, to be made visible. I have shown that health-related mobilities can have motivations that go beyond the logics of access and healing. However, the limited number of patients involved in this part of the research meant that I was able to highlight only the major trends of intranational health-related mobility in 
Italy. A larger study could have the advantage of making more visible also the role of micromobilities, and the interplay between different kinds of mobilities and different kinds of treatments. In the case of breast cancer, this could, for example, involve exploring the kinds of mobility enacted for each segment of the treatment - surgery, chemotherapy, radiotherapy, reconstruction (concurrent with surgery or delayed and with different techniques, not all of which are equally widespread), and follow-up. Some of the interviewees I met underwent only the initial surgery outside the region of residence and underwent all other treatments locally, while others travelled further to receive various treatments out of region. Longitudinal research would probably be the best way to understand how healthcare mobility and immobility combine in individual experiences.

Most interviewees treated in Southern Italy described their experience in very positive terms. Their positive accounts can be linked to local variations in the Italian healthcare system and reflect actual positive experiences, but they can also be linked to the need to avoid the dual stigma, both of the disease and of having failed to take adequate care of oneself. In the dominant neoliberal paradigm, the role of individual behaviors and lifestyles is presented as a central element in the development of several serious diseases. In the case of breast cancer, lifestyles are presented as a way of preventing the disease and early diagnosis is indisputably linked with a positive outcome of therapies. Even though different sociomedical studies have questioned these assumptions (Brown 2007), breast cancer awareness campaigns, and media discourses more generally, continue to spread the idea that individual behavior is central in the development of breast cancer. In this context, patients in Southern Italy have to deal with the further pressure of having to decide where they will be treated. The health-related mobilities I have illustrated in this article reflect the territorial inequalities of the two halves of the country, including both economic inequality and issues of symbolic 
hierarchy and stigma. I have shown that locally treated patients also moved between different provinces, and even those who were treated in their own province of residence often needed to navigate different local healthcare institutions. However the patients interviewed in the south, especially if they were treated in the south, had also to respond to a socially diffuse stigma against the territory and its population. Such a phenomenon is not unique to Italy. In other contexts, public healthcare can be stigmatized and needs to be re-evaluated in comparison to private healthcare because it is used by poorer or racialized parts of the population (cf. Lovell 2011). What is peculiar to the case presented here is the geographic stratification that is sustained within a national public system. The discourses mobilized by southern Italian patients include a moral re-evaluation of local doctors, or their legitimation through the doctors' mobility (rather than their own) to the north and back. This symbolic inequality between the north and the south filters into the illness experience of patients, and into the assessment of professional skill, with an impact on women's therapeutic trajectories.

The analysis of the experiences presented here offers the opportunity to reflect on the different meanings of the concept of "cure." While the concept of "healing" has more frequently been employed to discuss patients' experiences, this runs the risk of blackboxing the biomedical dimension of cure, leaving it outside of the scope of enquiry of medical anthropology. Interviewees demonstrated that seeking biomedical efficacy articulates meanings that are not limited to the disappearance of symptoms or the removal of pathological tissue. The efficacy of the cure also included therapies that the women considered to be more useful for their own case and, especially, healthcare institutions and doctors who were reliable, both from a technoscientific and a moral point of view. The honesty of doctors and patients' trust in them are important elements in patients' experiences. This is particularly relevant for breast cancer, in which "no evidence of disease" and the 
absence of relapse is the best obtainable outcome. When even the results of biomedicine are expressed in probabilistic terms, there are good reasons to include aspects such as seeking the best therapies within the domain of biomedical efficacy.

A patient's sense of what constitutes "cure" is linked to the places to which she moves to be treated, and to those where she remains. When a territory is stigmatized, this stigma also affects local healthcare services; therefore, finding therapeutic contexts that one can consider reliable, and that one can present to others as reliable, leads to searching for good healthcare and employing specific discursive presentations of the healthcare received. This emerged in the language used by the interviewees. As noted above, spatial deixis was used by interviewees not only to signify physical spaces, but also symbolic spaces (Lotman 1973) constructed by the material and symbolic inequalities that have characterized the Italian territory since its unification. This deixis illustrates how southern women situate themselves and their illness experiences in relation to places.

This dimension is further reinforced by closer attention to the meaning given to "moving" in the interviews. Lucrezia lived in Lecce and was treated in Bari, while Claudia lived in Emilia-Romagna and was treated in Mantua and Pisa. In terms of kilometres, the two women were treated at comparable distances from home. However, Lucrezia said that she "remained here" while Claudia "went outside the territory." Other women treated in the south mentioned that they underwent some of their therapies in Brindisi rather than in Lecce; however, the intraregional mobilities of interviewees from Apulia were not considered "moving," regardless of the kilometres covered. Despite the different ranges of mobility, everything that does not include a movement to the north of the country was represented as "here." The only mobility recognized by interviewees from the south as "moving" was to the north of the country, as it allows them to complete a symbolic leap and undergo treatments 
that would be considered by others as "adequate" if not excellent. A different symbolic redefinition of cures was undertaken by patients who remained in the south, by bringing the south into the domain of modernity. Chambers (2015) emphasizes that Southern Italy, like all "souths," does not sit outside of modernity, but is part of the structural inequalities that form the basis of capitalist modernity. The patients I met in Southern Italy seemed to reappropriate this idea. Through the circulation of doctors, the homogeneity of biomedicine or an emphasis on the morality of the south, or of people in the south, they redefined the place where they were treated, and their experience of their treatments, as valid and appropriate. This suggests that the experience of cure is defined not only in biomedical terms, but also in geographic, political and symbolic terms.

\section{ACKNOWLEDGEMENTS}

I wish to thank Anne M. Lovell, Ilana Löwy, Carsten Timmermann and Djordje Sredanovic, as well as the three anonymous reviewers of Medical Anthropology and Lenore Manderson for their precious comments and suggestions on previous versions of the paper; all shortcomings remain obviously mine.

\section{FUNDING}

The data here presented are the result of a research funded through an SHS scholarship of the Cancéropôle Île-de-France; I further benefited from a Barbara Rosenblum Dissertation Scholarship for the Study of Women and Cancer for further analyses of the data. This article was finalized while I was a Newton International Fellow of the British Academy at the University of Manchester. 


\section{References}

Balzi, D., M. Geddes and L. Lispi

2002 La "migrazione sanitaria" per tumore alla mammella fra le regioni italiane. Roma, Italy: Ministero della Salute.

Banfield, E.C.

1958 The Moral Basis of a Backward Society. New York: Free Press.

Barakat, F.H., I. Suleiman and M.A. Sughayer

2014 Reliability of frozen section in breast sentinel lymph node examination. Breast Cancer 21(5): 567-582.

Brown, P.

2007 Toxic Exposures: Contested Illnesses and the Environmental Health Movement New York: Columbia University Press.

Buonomo, A. and G. Gabrielli

2016 Why do they move? Characteristics and determinants of internal mobility in Italy. Polis 30(2): 153-180.

Burawoy, M.

1991 The extended case method. In Ethnography Unbound. Power and Resistance in the Modern Metropolis, M. Burawoy et al., eds. Pp. 271-290. Berkeley, CA: University of California Press.

Castañeda, $H$.

$2010 \mathrm{Im} /$ Migration and health: Conceptual, methodological, and theoretical propositions for applied anthropology. NAPA Bulletin 34(1): 6-27.

Chambers, I.

2015 The 'Southern Question' ... again. In The Routledge Handbook of Contemporary 
Italy: History, Politics, Society, A. Mammone, E.G. Parini and G.A. Veltri, eds. Pp. 13-22. New York: Routledge.

Cimino, G. and R. Foschi.

2014 Northerners versus Southerners. Italian anthropology and psychology faced with the “Southern Question.” History of Psychology 17(4): 282-295.

Clough, K.B., G.J. Kaufman, C. Nos, I. Buccimazza and I.M. Sarfati.

2010 Improving breast cancer surgery: A classification and quadrant per quadrant atlas for oncoplastic surgery. Annals of Surgical Oncology 17(5): 1375-1391.

Dalstrom, M.D.

2012 Winter Texans and the Re-creation of the American Medical Experience in Mexico. Medical Anthropology 31(2): 162-177.

2013 Medical travel facilitators: connecting patients and providers in a globalized world. Anthropology \& Medicine 20(1): 24-35.

Finkler, K.

2000 Diffusion reconsidered: Variation and transformation in biomedical practice, a case study from Mexico. Medical Anthropology 19(1): 1-39.

Galasso, G.

2006 SVIMEZ, Mezzogiorno, un sessantennio di storia italiana. Rivista economica del Mezzogiorno 3-4: 423-444.

Gabriele, S.

2015 Crisi, austerità, sistemi sanitari e salute nei Paesi dell'Europa meridionale. Meridiana 83: 63-90.

Glick Schiller, N. and N.B. Salazar. 
2013 Regimes of mobility across the globe. Journal of Ethnic and Migration Studies 39(2): 183-200.

Gramsci, A.

1966 La questione meridionale. Roma, Italy: Editori Riuniti.

Greco, C.

2016 Blaming the southern victim: Cancer and the Italian 'Southern Question' in Terra dei fuochi and Taranto. Anthropology Today 32(3): 16-19.

Kangas, B.

2002 Therapeutic itineraries in a global world: Yemenis and their search for biomedical treatment abroad. Medical Anthropology 21(1): 35-78.

2007 Hope from abroad in the international medical travel of Yemeni patients. Anthropology \& Medicine 14(3): 293-305.

Kaufman, V., M.M. Bergman and D. Joye

2004 Motility: Mobility as Capital. International Journal of Urban and Regional Research 28(4): 745-756.

Leivestad, H.H.

2016 Motility. In Keywords of Mobility: Critical Engagements. N.B. Salazar and K. Jayaram, eds. Pp. 133-151. New York: Berghahn.

Liberati, A., G. Apolone, A. Nicolucci, C. Confalonieri, R. Fossati, R. Grilli, V. Torri, P. Mosconi and A. Alexanian.

1991 The role of attitudes, beliefs, and personal characteristics of Italian physicians in the surgical treatment of early breast cancer. American Journal of Public Health 81(1): $38-42$. 


\section{Lotman, I.}

1973 La structure du texte artistique. Paris, France: Gallimard.

Lovell, A.M.

2011 Debating life after disaster: Charity Hospital Babies and bioscientific futures in postKatrina New Orleans. Medical Anthropology Quarterly 25(2): 254-277.

Löwy, I.

2007 The social history of medicine: Beyond the local. Social History of Medicine 20(3): 465-481.

Mapelli, V.

2012 Il sistema sanitario italiano. Bologna, Italy: Il Mulino.

Mol, A.

2008 The Logic of Care. Health and the Problem of Patient Choice. London: Routledge.

Mol, A. and M. Berg

1998 Differences in medicine: An introduction. In Differences in Medicine: Unraveling Practices, Techniques, and Bodies, M. Berg and A. Mol, eds., Pp. 1-12. Durham, NC: Duke University Press.

Molina, R.L. and D. Palazuelos.

2014 Navigating and circumventing a fragmented health system: The patient's pathway in the Sierra Madre region of Chiapas, Mexico. Medical Anthropology Quarterly 28(1): $23-43$.

Parkin, D.

2014 Pathways to healing: Curative travel among Muslims and non-Muslims in Eastern East Africa. Medical Anthropology 33(1): 21-36.

Pian, A. 
2015 Care and migration experiences among foreign female cancer patients in France: Neither medical tourism nor therapeutic immigration. Journal of Intercultural Studies 36(6): 641-657.

Pica, F. and S. Villani

2010 Questioni concernenti la nozione di costo standard: la mobilità dei pazienti e le mode sanitarie. Rivista economica del Mezzogiorno 23(3): 397-422.

Roberts, E.F.S. and N. Scheper-Hughes

2011 Introduction: Medical migrations. Body \& Society 17(2-3): 1-30.

Salazar, N.B. and A. Smart

2011 Anthropological takes on (im)mobility. Identities 18(6): i-ix.

Sargent, C. and S. Larchanché

2011 Transnational migration and global health: The production and management of risk, illness and access to care. Annual Review of Anthropology 40: 345-361.

Schneider, J., ed.

1998 Italy’s ‘Southern Question’: Orientalism in one country. Oxford, UK: Berg.

Sobo, E.J.

2009 Medical travel: What it means, why it matters. Medical Anthropology 28(4): 326335.

Sobo, E.J., E. Herlihy and M. Bicker

2011 Selling medical travel to US patient-consumers: the cultural appeal of website marketing messages. Anthropology \& Medicine 18(1): 119-136.

\section{SVIMEZ}

2014 Rapporto SVIMEZ sull'economia del Mezzogiorno. Bologna, Italy: Il Mulino. Toth, F. 
2014 How health care regionalisation in Italy is widening the North-South gap. Health Economics Policy and Law 9(3): 231-249.

Urry, J.

2007 Mobilities. Cambridge, UK: Polity.

Viesti, G.

2001 Un Mezzogiorno diverso. Il Mulino 4: 700-710.

Vindrola-Padros, C.

2012 The everyday lives of children with cancer in Argentina: Going beyond the disease and treatment. Children \& Society 26(6): 430-442.

Vindrola-Padros, C. and E. Brage

2016 Child medical travel in Argentina: Narratives of family separation and moving away from home. In Children's Health and Wellbeing in Urban Environments. C.R. Engler, R. Kearns and K. Witten, eds. Pp. 128-144. London: Routledge.

Vindrola-Padros, C. and G.A. Johnson

2017 Children Seeking Health Care: International Perspectives on Children's Use of Mobility to Obtain Health Services. In Movement, Mobilities, and Journeys. C. Ní Laoire and A. White, eds. Pp. 289-306. Singapore: Springer.

Vindrola-Padros, C. and L.M. Whiteford

2012 The search for medical technologies abroad: The case of medical travel and pediatric oncology treatment in Argentina. Technology and Innovation 14(1): 25-38.

Waldram, J.B.

2000 The Efficacy of Traditional Medicine: Current Theoretical and Methodological Issues. Medical Anthropology Quarterly 14(4): 603-625.

Whittaker, A., L. Manderson and E. Cartwright 
2010 Patients without borders: Understanding medical travel. Medical Anthropology 29(4): 336-343.

Young, A.

1982 The anthropologies of illness and sickness. Annual Review of Anthropology 11: $257-285$

Zorzi, M. and S. Guzzinati

2011 Screening mammografico e riduzione dei tassi di mastectomie. In Come cambia l'epidemiologia del tumore della mammella in Italia. I risultati del progetto IMPATTO dei programmi di screening mammografico, E. Pacini and D. Puliti, eds., Pp. 67-72. Pisa, Italy: Pacini.

\section{Captions}

Figure 1. Location of the cities and regions mentioned in the article 